\title{
Rubric Based Individual Itemized Assessment of Academic Projects
}

\author{
B. Surendra Reddy \\ ${ }^{1}$ Department of Computer Science, Hyderabad Institute of Technology and Management, Hyderabad \\ ${ }^{1}$ surendra.mca@hitam.org
}

\begin{abstract}
Majority of the students graduated from engineering colleges in India fail to justify their grades given to their project work. Academic Projects of 3 to 6 months duration are often offered to them to fulfill the course requirement. Developing a systematic assessment scheme helps the students to work on the expectations and teachers to grade within the set criteria. Existing system of project evaluation merely covers the basic things like abstract, technical and documentation reviews with a generalized grading policy. This paper is an attempt to help the teachers design a rubric considering specific modules to effectively assess the project work. Students can plan their work schedule and anticipate the expectations based on the rubric supplied to them. Job of the teachers is complex during the design of rubric but becomes quite simple when actual grading takes place.
\end{abstract}

Keywords: Rubric, Assessment, Academic Project, Grading policy

\section{B. Surendra Reddy}

Department of Computer Science Engineering, Hyderabad Institute of Technology and Management

surendra.mca@hitam.org

\section{Introduction}

Guidelines given to the teachers of engineering colleges in India regarding evaluation of the students' academic projects lack precisely set criteria. Particularly, students are confused to conclude the individual components of the projects as they do not know where to stop. Some teachers deduce specific guidelines from the general guidelines to make the job simple. It is possible that diversified perceptions take place with teachers when they go through the set criteria (Brown, Knight, 1994). The objective of this paper is to encourage the teachers to design a sophisticated rubric that decrease the gap between teacher's expectation and student's delivery. Rubric is a mean of communicating expectations for an assessment item. There are various types of rubrics such as check lists, basic rating scales, holistic rating scales and analytic rating scales.

\section{Methodology}

We used academic project as an assessment item in this context. The rubric was designed by finalizing the individual items of the entire work and further into sub items for utmost preciseness. List of items given in the general guidelines were used to prepare the criteria of evaluation. Brainstorming all the possible rating scales for the student outcomes helped in arriving at a conclusion of preparation a list of rating scales. List contained entire range of possibility. It started with the worst possibility and ended with the best possibility. All the other discrete possibilities were put in between. The number of rating scales for each sub item was finalized by discarding the unjustified ones. It was advised to restrict the scale to maximum of FIVE to reduce the confusion of discrimination between the adjacent rating scales. Topics were further decomposed when the rating scales exceeded FIVE to ensure the clarity of the scales. The next task was to describe the expectations under each rating scale independently. Unambiguous verbs and quantifiers were used to describe the expectations.

Number of rating scales to individual sub itemized criteria varied based on the listed possibilities of the set expectations. All the descriptions of expectations are in 
sync with the Program Objectives and Course Learning Outcomes. The rubric was revised using self review and peer or expert review to arrive at the complete rubric to assess the academic project. Students started designing rubrics for their other works. They initially started with checklists and even went to an extent of designing holistic and analytic rubrics. Teacher who had an opportunity to review the rubric learnt new ways of looking at the setting criteria. Many refinements had taken place after considering the feedback of multiple reviews. The following is a piece of such description under each rating scale.

As a case, we considered the academic project of $3^{\text {rd }}$ year under graduate engineering students. They have to carry out the project within a span of three to four months. A common check list is prepared by the instructor, before designing a holistic rubric for assessment of the project work.

Table1: Checklist for the Academic Project Work

\begin{tabular}{|c|c|c|}
\hline Topic & Sub Topic & $\begin{array}{l}\text { Max } \\
\text { Marks }\end{array}$ \\
\hline \multirow{5}{*}{ Analysis } & $\begin{array}{l}\text { Description of the } \\
\text { Problem }\end{array}$ & 2 \\
\hline & Objectives & 3 \\
\hline & $\begin{array}{l}\text { Description of Existing } \\
\text { Solution }\end{array}$ & 2 \\
\hline & $\begin{array}{l}\text { Evaluation of Existing } \\
\text { Solution }\end{array}$ & 2 \\
\hline & $\begin{array}{l}\text { Description of other } \\
\text { possible Solutions }\end{array}$ & 2 \\
\hline \multirow{5}{*}{ Design } & Action Plan & 3 \\
\hline & System Flowchart & 2 \\
\hline & Databases & 3 \\
\hline & Data Flow Diagrams & 3 \\
\hline & $\begin{array}{l}\text { Description of method of } \\
\text { solution }\end{array}$ & 3 \\
\hline \multirow{3}{*}{ Implementation } & $\begin{array}{l}\text { Method of solution related } \\
\text { to problem }\end{array}$ & 2 \\
\hline & $\begin{array}{l}\text { Accurate method of } \\
\text { solution }\end{array}$ & 3 \\
\hline & Programming Code & 3 \\
\hline \multirow{2}{*}{ Testing } & Testing Strategy & 3 \\
\hline & Test Results & 4 \\
\hline \multirow{2}{*}{ Documentation } & Technical Documentation & 2 \\
\hline & User Guide & 3 \\
\hline \multirow{2}{*}{ Evaluation } & Evaluation & 3 \\
\hline & Future Development & 2 \\
\hline
\end{tabular}

Topics have been classified into six distinguished categories from Analysis through Evaluation as shown in Table 1. Topics are further divided into sub topic and listed in the checklist. Instructors set the marks to each sub topic and arrive at a conclusion on the total marks to be considered for the entire project work.Individual sub topics are taken for designing the final rubrics.
Table2: Rubric for award of grade to Description of the Problem Statement in an Academic Project

\begin{tabular}{|l|l|l|l|}
\hline S.No & Sub Topic & Expected Outcome & Credits \\
\hline 1 & $\begin{array}{l}\text { Description of } \\
\text { the Problem }\end{array}$ & $\begin{array}{l}\text { Brief description of the } \\
\text { Business Organization }\end{array}$ & 1 Mark \\
\hline 2 & $\begin{array}{l}\text { Description of } \\
\text { the Problem }\end{array}$ & $\begin{array}{l}\text { Description of the } \\
\text { Business Organization , } \\
\text { together with the nature } \\
\text { of the problem to be } \\
\text { solved }\end{array}$ & Marks \\
\hline
\end{tabular}

Table 2 shows the rubric for grading a sub topic of an academic project in a four year under graduate engineering course in computer science engineering on a scale of two marks. The only choice for a teacher to assess without the rubric is very discrete. If it is felt to award either full or partial or null the same is followed. Even the student's mind is uncertain before submission of the work for grading.

Table3: Rubric for award of grade to Objectives

\begin{tabular}{|l|l|l|l|}
\hline S.No & Sub Topic & Expected Outcome & Credits \\
\hline 1 & Objectives & $\begin{array}{l}\text { Objectives listed in } \\
\text { general business terms. } \\
\text { E.g., to make process run } \\
\text { faster, save resources }\end{array}$ & \\
\hline 2 & Objectives & $\begin{array}{l}\text { Objectives are listed in } \\
\text { terms of computer terms. } \\
\text { E.g., creating database, } \\
\text { sort and search etc. }\end{array}$ & 2 Marks \\
\hline 3 & Objectives & $\begin{array}{l}\text { Objectives listed in both } \\
\text { generic and computer } \\
\text { related terms }\end{array}$ & 3 Marks \\
\hline
\end{tabular}

Scope of student thinking towards writing both generic and computer related objective is increased with the help of the rubric shown in Table 3.

Table 4: Rubric for award of grade to Test Results

\begin{tabular}{|c|c|c|c|}
\hline S.No & Sub Topic & Expected Outcome & Credits \\
\hline 1 & $\begin{array}{l}\text { Test } \\
\text { Results }\end{array}$ & One type of data tested & 1 Mark \\
\hline 2 & $\begin{array}{l}\text { Test } \\
\text { Results }\end{array}$ & Two types of data tested & 2 Marks \\
\hline 3 & $\begin{array}{l}\text { Test } \\
\text { Results }\end{array}$ & Three types of data tested & 3 Marks \\
\hline 4 & $\begin{array}{l}\text { Test } \\
\text { Results }\end{array}$ & $\begin{array}{l}\text { All the three types of data } \\
\text { tested covering all the } \\
\text { functional aspects like } \\
\text { data input, processing and } \\
\text { output }\end{array}$ & 4 Marks \\
\hline
\end{tabular}

The three rubrics mentioned in the above tables 2,3 and 4 covering 2 Marks, 3 Marks and 4 Marks schemes. The holistic rubric is shared under Annexure-I.

\section{Results}

As we used analytical rating scale for assessing academic project, we could see relief in students. Teachers became more conscious to set expectations at itemized level. Increased accountability was witnessed as unclear, meaningless or instant items had been avoided. Students could check their work time to time on their own. There 
were no surprises when they received grades. Feedback was provided instantly using the same rubric as an assisting tool for both student and teacher. The tool provided transparency among the students to explore and analyze their grades. Grievances and discrepancies related to comparison of grades had been reduced. Average grades were improved. Lot of time of the students was saved when they followed the rubric. Some of the students got their projects reviewed by their friends before submitting for final review by the teacher. I failed to collect numerical evidences of my experience in designing and implementing the individual itemized rubric.

\section{Discussion}

A situation when there was no rubric is described here. Students were focusing more on the areas where they liked. Few parts were ignored which were actually critical for the project. This happened as there was no way to know the break point. Quantity was more and some students felt they had done a wonderful work. Final grades made them unhappy as their work had not met the expectations. Of course the expectations were not precise and sometimes those were secrets. There instances where instant criteria was set on the spot of assessment. Even this varied from teacher to teacher, course to course and at times varied by the same teacher based on the time. There could be lot of difference between what is spoken in theory and what actually happens in practice. But as a whole, Itemized rubric sets the break point even for the highest rating scale. Students understood where to stop exactly and also what would they lose if they ignore a specific item.

\section{Conclusion}

Students deserve well defined criteria before they actually start working on their projects. Any judgment cannot be considered fair unless criteria are logically followed. Criteria should not be a secret and be open to all. Perceptions of people (both students and teachers) may lead to further learning in creating more meaningful rubrics for assessing academic projects. The findings of rubric designing process described in this paper would certainly help teachers in higher education to start use their own rubrics to evaluate the students work.

\section{Recommendations}

Rubric document may be supplied to all the students as they start their project. The same may be made available online for quick reference. Mentioning of tentative timelines and estimated time to be spent on each sub item will help the learners to benchmark their time management. Take feedback of the students who followed the rubric and not followed (Sadler, 2005). Compile an analysis report for making further improvements in the rubric. Numerical evidences may be recoded scientifically to show the impact of the tools used for assessment. The experiment can be scaled to the entire program and even to institution level.
Sincere thanks to IUCEE for facilitating the Engineering Teachers to enhance their teaching skills by creating a common platform. The Author extends his gratitude to Dr. Subrahmanyam Rajan of Arizona State University for being inspirational and provoked to convert the thought into a paper.

\section{References}

Sadler, D. R. (2005). Interpretations of criteria-based assessment and grading in higher education. Assessment \& Evaluation in Higher Education

Brown, S. \& Knight, P. (1994) Assessing learners in higher education (London, Kogan Page). Coombs, C. H. (1964) A theory of data (New York, Wiley).

\section{Web References}

http://www.academicprograms.calpoly.edu/content/accred progrev/progrev_bacc/sp2_guidelines

https://www.cmu.edu/teaching/assessment/examples/course level-bycollege/hss/tools/jeria.pdf

\section{Acknowledgement}

